\title{
A rare consequence of trauma: Chylothorax
}

\author{
HILAL HOCAGIL, ABDULLAH CÜNEYT HOCAGIL, GÜLESER AKPINAR
}

Bulent Ecevit University, Faculty of Medicine, Department of Emergency Medicine, 67600 Zonguldak, Turkey

Corresponding Author:

Hilal Hocagil

Bulent Ecevit University, Faculty of Medicine. Department of Emergency Medicine

67600 Zonguldak, Turkey

Phone: +90 5053544434

E-mail:drhocagil@gmail.com

\section{ABSTRACT}

Chylothorax is defined as the lymphatic fluid accumulation in the pleural space due to the obstruction or injuries in the ductus thoracicus. The incidence of chylothorax due to blunt and penetrating traumas is low at a rate of $0.2-3 \%$. This case presentation intends to evoke chylothorax as a rare cause of pleural effusion due to injuries.

A 27-day-old infant was brought to the emergency department with the complaint of a sudden respiratory distress developing after falling off the couch. The respiratory rate was 62 , the pulse rate was 174 , and the oxygen saturation rate was $68 \%$. In the physical examination, the respiratory sounds were diminished bilaterally. The patient was intubated. As the saturation levels did not improve after intubation, a needle aspiration was performed bilaterally in the anterior axillary line with a prediagnosis of massive haemothorax. A yellowish fluid was aspirated from the pleural space bilaterally. Chest tubes were inserted bilaterally to treat respiratory distress due to mass effect of chylothorax. Massive chylothorax cases may result in serious complications leading to respiratory distress and cardiac dysfunction. An early diagnosis and appropriate treatment can be lifesaving in these patients.

Key words: chylothorax, trauma, pleural effusion

\section{INTRODUCTION}

Chylothorax is defined as the lymphatic fluid accumulation in the pleural space due to the obstruction or injuries in the ductus thoracicus. It may occur in association with non-traumatic or traumatic causes. (1) Traumatic chylothorax develops in association with iatrogenic causes at a rate of $80 \%$. The incidence of chylothorax due to blunt and penetrating traumas is low at a rate of $0.2-3 \%$. $(2,3)$ These figures are lower in children compared to those observed in adults. Delays in the diagnosis or treatment failures may lead to complications including physiological abnormalities, nutrition disorders or immunosuppression. The mass effect may cause respiratory distress and cardiac function in massive chylothorax cases. (3)

This case presentation intends to evoke chylothorax as a rare cause of pleural effusion due to injuries.

\section{CASE PRESENTATION}

A 27-day-old infant was brought to the emergency department with the complaint of a sudden respiratory distress developing after falling off the couch. The respiratory rate was 62 , the pulse rate was 174 , and the oxygen saturation rate was $68 \%$. In the physical examination, the respiratory sounds were diminished bilaterally. The patient was intubated. As the saturation levels did not improve after intubation, a needle aspiration was performed bilaterally for massive haemothorax. A yellowish fluid was aspirated from the pleural space bilaterally (Figure1). Chest tubes were inserted bilaterally with the prediagnosis of traumatic chylothorax to treat respiratory distress due to mass effect of pleural fluid. The high triglyceride level $(117 \mathrm{mg} / \mathrm{dL})$ in pleural effusion analysis allowed for making a definite diagnosis. A thorax computed tomography $(\mathrm{CT})$ revealed a massive effusion bilaterally. There were not any other pathologic findings. The patient was admitted to the pediatric intensive care unit (ICU). Oral intake of the patient stopped and total parenteral nutrition started. The patient was treated with antibiotics in the ICU for a period of one week. At the end of this period the chest tubes were withdrawn and chylothorax did not recur. The patient was discharged from the hospital in a health state.

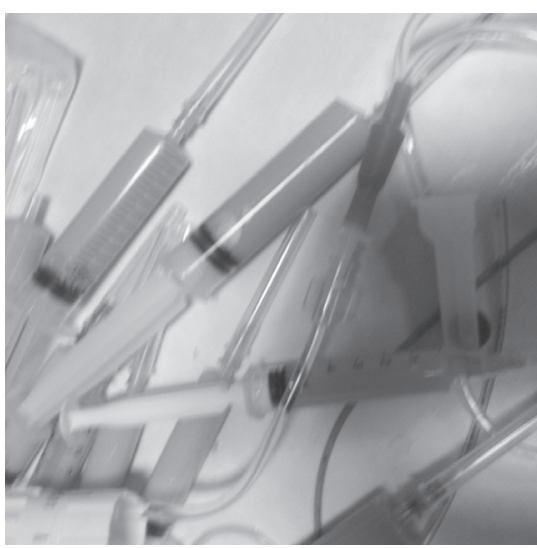

Figure 1. Yellowish fluid aspirated from the pleural space bilaterally

\section{DISCUSSION}

Traumatic ductus thoracicus injuries are rare as it is protected in the thoracic cage. Ductus thoracicus injuries associated with blunt injuries often occur due to bone fractures. The most common etiologic mechanism in the newborn is the injuries to the ductus thoracicus caused by the hyperextending thoracic vertebrae. (4) The development of bilateral chylothorax in our patient in the absence of fractured vertebrae or ribs suggested that the vertebrae might have injured the ductus thoracicus. As the patient was a newborn, congenital factors would be considered in the differential diagnosis. However, the labour was performed in a university hospital and the patient was evaluated by paediatricians as a completely healthy newborn and discharged. Furthermore, the sudden development of respiratory distress immediately after falling off the couch suggested that this finding developed due to trauma. The presence of blunt trauma and the falling of an immobile infant off the couch raised suspicions of the cause of the event and led to the investigation for any signs of child abuse. Although not definitely exclusive, the absence of physical abuse 
signs, such as widespread ecchymoses developing at temporally different time points, fractures in the long bones or ribs, or cranial trauma (6) in our patient excluded the diagnosis of child abuse. However, the absence of a funduscopic examination and the forensic medicine consultation are the missing points to be improved in the evaluation of our patient.

Chylothorax should be considered in the differential diagnosis of the patients with thorax radiograms showing pleural effusion and should be included in a history of recent thoracic surgery or traumas to the neck, trunk or upper abdomen. Chylothorax is often diagnosed incidentally in the samples collected from the pleural effusion. The milky appearance of the pleural effusion is important in making the diagnosis but it may be misleading as it is seen only in $50 \%$ of the chylothorax patients and a cholesterol effusion also creates the same appearance. The triglyceride levels over $110 \mathrm{mg} / \mathrm{dL}$ in the pleural fluid sample will clarify the diagnosis. The diagnosis of chylothorax is excluded in the patients with triglyceride levels below $50 \mathrm{mg} / \mathrm{dL}$ in the pleural effusion sample, however, a lipoprotein electrophoresis should be performed to investigate the presence of chylomicrons in the pleural effusion sample when the levels range from 50 to 119 $\mathrm{mg} / \mathrm{dL}$. The detection of chylomicrons is conclusive for a definite diagnosis but the technique is not employed in the routine practice since it is expensive, not practical, and not available widely. (7)

The diagnosis was made incidentally in this patient. A milky pleural effusion was collected. The high triglyceride level $(117 \mathrm{mg} /$ $\mathrm{dL}$ ) in pleural effusion analysis allowed for making a definite diagnosis.

Computed tomography of the thorax, abdomen, and pelvis should be obtained in the chylothorax patients so that the underlying etiology will be determined and the interventional or surgical procedures will be scheduled. Lymphangiography is a contrast-enhanced imaging technique allowing for visualising the structure of the ductus thoracicus and the potential area of injury. (8)

The treatment of chylothorax is scheduled according to the underlying aetiology but the patient was swiftly evaluated as it is performed for all trauma patients according to the Advanced Trauma Life Support guidelines. A tube thoracostomy is performed in all patients with unstable hemodynamics and respiratory failure due to the presence of pleural effusion. Thoracentesis may also be sufficient in patients with stable haemodynamic findings. In addition, total parenteral nutrition, wide-spectrum antibiotics and octreotide therapies are administered. Conservative approaches are successful in $50 \%$ of the non-surgical traumatic chylothorax cases.

A surgical intervention is indicated in the patients showing no improvement despite the administration of conservative therapies and relatively longer periods of drainage. (8) The ligation of the ductus thoracicus allows for achieving success. Chemical pleurodesis is another promising treatment option when the injured site of the ductus thoracicus cannot be detected. (9)

\section{CONCLUSION}

Chylothorax is a rare cause of pleural effusion associated with non-surgical traumas. Massive chylothorax cases may result in serious complications leading to respiratory distress and cardiac dysfunction. An early diagnosis and appropriate treatment can be life-saving in these patients.

\section{REFERENCES}

1. Rajdev K, Avula A, Sharma D, Mansour W, Agarwal S, Siddiqui AH, et al. A case of transudative chylothorax: a diagnostic dilemma. Cureus 2018;10(2): e2247.

2. Miller JI. Anatomy of the thoracic duct and chylothorax. In Shields of TW locicero J Po RB, Rusch VW, editors. General Thoracic Surgery. 6th ed. Philadelphia: Lippincott Williams and Wilkins 2005.p. 879-88.

3. Pillay TG, Singh B. A review of traumatic chylothorax. Injury 2016;47:545-50.

4. Idris K, Sebastian M, Hefny AF, Khan NH, Abu-Zidan FM. Blunt traumatic tension chylothorax: case report and mini-review of the literatüre World J Clin Cases 2016;4:380-4.

5. Van Rijn RR, Spevak MR. Imaging of neonatal child abuse with an emphasis on abusive head trauma.Magn Reson Imaging. Clin $\mathrm{N}$ Am 2011;19:791-812.

6. Kara B, Biçer Ü, Gökalp AS. Child abuse. Review. Journal of Child Health and Diseases 2004;47:140-51.

7. Maldonado F, Hawkins FJ, Daniels CE, Doerr CH, Decker PA, Ryu JH. Pleural fluid characteristics of chylothorax. Mayo Clin Proc 2009;84:129.

8. Maldonado F, Cartin-Ceba R, Hawkins FJ, Ryu JH. Medical and surgical management. Am J Med Sci 2010;339:314.

9. Sendama W, Shipley M. Traumatic chylothorax: A case report and review. Respir Med Case Rep 2015;14:47-8. 